\title{
Comparison between open-site and below-canopy climatic conditions in Switzerland for different types of forests over 10 years (1998-2007)
}

\author{
V. Renaud • J. L. Innes • M. Dobbertin • M. Rebetez
}

Received: 21 May 2010 / Accepted: 20 October 2010/Published online: 16 December 2010

(C) Springer-Verlag 2010

\begin{abstract}
We compared below-canopy and open-site climatic conditions for 14 different forest sites in Switzerland and analysed the forest influence on local summer and winter climate according to the forest type (coniferous, mixed, deciduous), soil type, slope orientation, basal area and tree height. We compared below-canopy and open-field data for minimum, maximum and daily mean temperature, relative humidity, maximum and daily mean photosynthetically active radiation (PAR) and wind speed from 1998 to 2007. We found clear differences between below-canopy and open-field temperatures, humidity, wind speed and PAR and could relate them to the specific site conditions and forest type. The forest influence on PAR and maximum temperature is clearly determined by the forest type, whereas the influence on minimum temperature is affected by both forest type and slope orientation and impact on humidity depends on the soil type. The wind speed is most impacted by topography and slope orientation.
\end{abstract}

V. Renaud $\cdot$ M. Rebetez $(\bowtie)$

WSL Swiss Federal Research Institute,

CP 96, 1015 Lausanne, Switzerland

e-mail: rebetez@wsl.ch

\section{J. L. Innes}

Department of Forest Resources Management,

Faculty of Forestry, The University of British Columbia,

2nd Floor, Forest Sciences Centre \#2045-2424, Main Mall,

Vancouver, British Columbia, Canada V6T 1Z4

\section{Dobbertin}

WSL Swiss Federal Research Institute,

Zurcherstrasse 111,

8903 Birmensdorf, Switzerland

\section{Introduction}

Forests are well-known for their moderating effect on below-canopy local climate, generally allowing lower maximum temperature and wind speed as well as higher minimum temperature and humidity (Aussenac 2000; Chen et al. 1999; Geiger et al. 2003; Lee 1978; Rebetez et al. 2004). The impact of the canopy on solar radiation and, as a result, on temperature, is the main driver of the forestclimate interactions (Bastable et al. 1993; Holst et al. 2004; Renaud and Rebetez 2009). A better understanding of these impacts is particularly important in the context of climate change, as forest ecosystems are expected to change and adapt to future climate conditions. As part of this adaptation, changes in below-canopy microclimate can be expected. Knowledge of the impact of different forest types on below-canopy climate will enable the better forecasting of future below-canopy climates, which in turn will enable the better modelling of ecosystem changes in forests. Whether naturally regenerated or planted, tree seedlings and saplings are most sensitive to the local microclimatic conditions. Available light, water supply and temperature determine the success or failure of most tree species. Wind measurements below the canopy are essential to estimate plant transpiration; they also help to detect if air flow underneath the trees leads to air mixing and thus to a reduced climatic gradient between canopy and the soil. It is therefore important to gain a better understanding of how forest structure alters microclimate.

Most forest climate analyses are based on a single forest type or dominant tree species: mixed deciduous forests (Grimmond et al. 2000), mixed conifer forests (Friedland et al. 2003), Douglas-fir (Chen and Franklin 1997), oak (Morecroft et al. 1998), beech (Holst et al. 2004) or pine (Pavari 1959; Porte et al. 2004). The impact of these 
different species on local climate varies and not all have a significant impact on temperature and humidity. Comparisons between below-canopy and open-field for various forest types are very limited, and they generally provide little information about the differential impacts of multiple species (Xia et al. 1999) or provide a comparison between only two species (Merklova and Bednarova 2007). A detailed comparison between several forest types and sites has been made for temperature during the summer 2003 heat wave in Switzerland, revealing the different impacts of forest types (coniferous, deciduous or mixed) and the dominant tree species (beech, oak, spruce or pine) on maximum and minimum temperature (Renaud and Rebetez 2009). Some studies have shown that aspect could also have a significant impact on below-canopy temperature (Holst et al. 2005). During the 2003 heat wave, north-facing forests had a greater impact on minimum temperatures than south-facing ones (Renaud and Rebetez 2009). The difference between open-field and below-canopy air humidity is less well documented. Some studies have found no significant correlation (Porte et al. 2004; Xia et al. 1999). There are strong differences between forest types (coniferous vs. deciduous) and species in the measured evapotranspiration rate (Komatsu 2005) and latent heat flux densities (Baldocchi and Vogel 1996), and the impact of the site characteristics may be even stronger (Matsumoto et al. 2008).

Most of these studies rely on a short observation period, generally less than 3 years, and often only one spring or summer season. Extrapolating and generalizing such results is always difficult. Our 10 years (1998-2007) of permanent observations on 14 different sites thus constitutes an unprecedented data series.

The main objective of the present study is to analyse the impact of the different forest types (coniferous, mixed, deciduous) on summer and winter microclimate. We also analyse the influence of two important constituents of the biogeographic context: slope orientation and soil type.

\section{Data and methods}

The meteorological data originated from 14 sites of the Swiss LWF (Long-term Forest Ecosystem Research) network (Renaud and Rebetez 2009), representing different ecological conditions within the six biogeographic zones of Switzerland (Table 1, Fig. 1). The long-term forest ecosystem sites in Switzerland were selected using the following criteria (Innes 1995): they should cover the most important forest types in Switzerland and/or being potentially sensitive to environmental change; they should be 2 ha in size and if possible have a rectangular shape, the sites should be homogeneous in soil type, vegetation cover and stand structure; the management type of the sites should be maintained for several decades; they needed to be accessible year-round, while not being next to a disturbances, such as heavily used roads. Measurements have been operated simultaneously below-canopy and at an approximately $1-\mathrm{km}$ distant open-field plot in a region of similar topography (altitude, slope orientation, distance from the bottom of valley, etc.). The reliability of the measurement instruments has been checked by comparison with data from MeteoSwiss stations (Logeay and Rebetez 1999), with excellent results. The thermometers and the humidity sensor were placed $2 \mathrm{~m}$ above ground, inside a circular metal box. Corrections were applied to relative air humidity and wind speed due to the two following instrumental problems: relative humidity rate could exceed $95 \%$ because the boxes were not protected against rain. The humidity sensors were calibrated every 2 years by the Swiss company Rotronic with an uncertainty of $1 \%$. The anemometers were $4.6 \mathrm{~m}$ above the ground and not $10 \mathrm{~m}$, so that wind speed was underestimated when it exceeded $2 \mathrm{~m} / \mathrm{s}$.

Temperature, radiation and wind speed were recorded every $10 \mathrm{~min}$, relative humidity every hour. The measurements for each site, available in real time, were stored in a relational database. Records are generally available from 1997 or 1998 , but only from 2000 at Chironico and three parameters (temperature, radiation and wind) are not available for 2000, 2001 and 2002 at Isone and Neunkirch. No PAR data are available for Novaggio.

We compared open-site and below-canopy measurements of photosynthetically active radiation (PAR) [W/ $\left.\mathrm{m}^{2}\right]$, air temperature $\left({ }^{\circ} \mathrm{C}\right)$, relative humidity $(\mathrm{RH})[\%]$ and wind speed $(\mathrm{m} / \mathrm{s})$ from 1998 to 2007 for 14 sites. We analysed minimum, maximum and average daily values for air temperature and humidity, maximum and average daily values for wind and PAR. We computed the correlation coefficient $r$ and applied Wilcoxon's tests (Bauer 1972) to check the significance level of the PAR, temperature, relative humidity and wind speed differences between open-field and below-canopy values for the whole period, annual, summer and winter averages.

We used leaf area index (LAI) values (Schleppi et al. 2007) for a comparison of the canopy closure degree between the different plots measured near the below-canopy meteorological station in 2004 (except at Beatenberg, measured in 2001).

We applied an ANOVA test to check the influence of the soil type on the differences between below-canopy and openfield air humidity. We also applied an ANOVA test to check the influence of dominant species, forest type, stand basal area $(G)$ $\left[\mathrm{m}^{2} / \mathrm{ha}\right]$, tree height $(\mathrm{m})$ and aspect on discrepancies between below-canopy and open-field maximum and minimum temperature and on maximum wind velocity. 


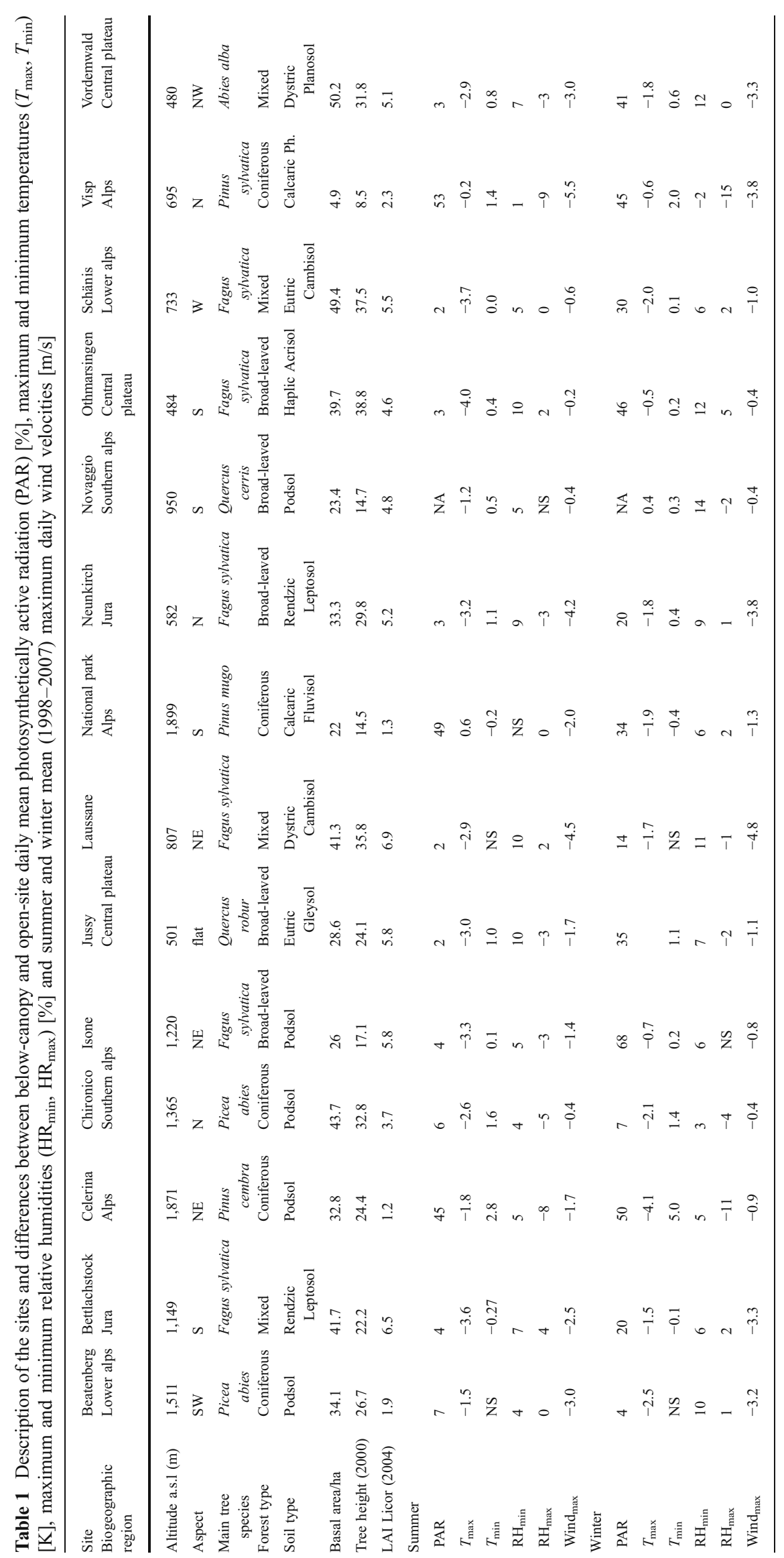


Fig. 1 LWF (Long-term Forest Ecosystem Research) plots distribution

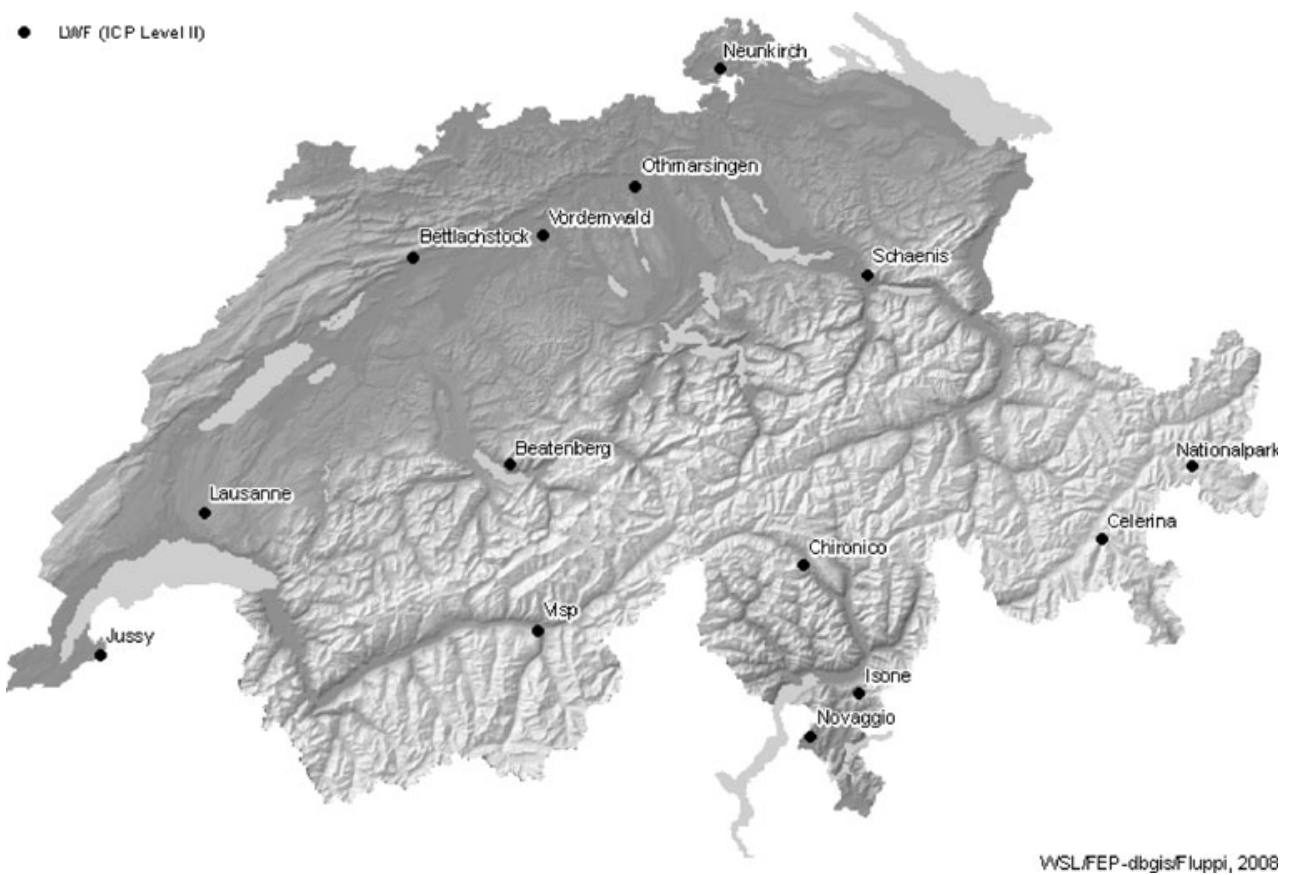

\section{Results}

\subsection{Solar radiation}

Daily mean PAR is clearly lower below-canopy for 10 out of 13 sites (Table 1). The canopies of deciduous forests stop $96 \%$ to $98 \%$ of PAR in summer, and $32 \%-80 \%$ in winter. This seasonal difference does not exist in spruce forests which stop $93 \%$ to $96 \%$ PAR in winter compared to $92 \%$ to $93 \%$ in summer. Mixed forests generally stop PAR as much as deciduous forests in summer and as much as spruce stands in winter. Only ca. $50 \%$ of the PAR was stopped at each of the three pine sites. The results of the ANOVA test confirm the significance of the correlation between LAI values and these differences in PAR values.

\subsection{Temperature}

The difference between below-canopy and open-field temperature was generally highly significant $(p<0.0001)$ for maximum, minimum and daily mean temperatures $\left(T_{\max }, T_{\min }\right.$, $\left.T_{\text {mean }}\right) . T_{\max }$ were lower below-canopy in all forest types, except pine forests (Table 1). In summer, the greatest differences were measured under beech and beech-silver fir forests with values 6 to $8 \mathrm{~K}$ lower below-canopy compared to open-field. In winter, the difference was highest in the conifer sites at the subalpine level, where $T_{\max }$ values were frequently up to $9 \mathrm{~K}$ lower below-canopy compared to open-field.

The relationship between the open-field $T_{\max }$ and belowcanopy/open-field $T_{\max }$ difference was always negative and highly significant $(p<0.001)$ for deciduous and mixed forest sites, as illustrated by the beech forest site of Othmarsingen, also negative but less significant in the spruce forest of Chironico, whereas it was positive and less significant in the pine forests of Celerina and of the National Park (Fig. 2). The strength of the cooling effect in deciduous and mixed forests depended on the absolute value of $T_{\max }$ : the warmer the temperature, the stronger the influence of the forest. The pine forests of National Park and Visp in contrast had a warming effect. These effects were stronger from April to October 2003, i.e., during the exceptionally hot summer 2003 in Europe, than in any of the other summers (1998 to 2007; Fig. 3).

$T_{\min }$ values (Table 1) were clearly higher below-canopy in the north-oriented conifer sites, especially during winter when on average they were up to $6 \mathrm{~K}$ higher below-canopy. In the beech-silver fir and beech forests, the difference between open-field and below-canopy was minor (less than $1 \mathrm{~K}$ ) but still statistically significant $(p<0.05)$ minimum temperatures were lower $(\geq 0.6 \mathrm{~K})$ below-canopy in mixed forests and higher $(\geq 0.5 \mathrm{~K})$ in beech stands. In the oak stands, $T_{\min }$ values were higher than in the corresponding open-field plots $(1 \mathrm{~K})$. There was no seasonal variation in the impact of the forest on $T_{\min }$ in mixed and deciduous forests. Where $T_{\min }$ values were higher below-canopy than in the open-field, the difference was stronger during the hot summer of 2003 than during the other summers (1998 to 2007; Fig. 3).

Generally, $T_{\text {mean }}$ values were lower below-canopy in deciduous and mixed forests, 1 to $2 \mathrm{~K}$ in summer, up to $1 \mathrm{~K}$ in winter and on a yearly average. They were higher in conifer forests, up to $1 \mathrm{~K}$ in summer, 2 to $3 \mathrm{~K}$ in winter in the south-oriented conifer sites. At some deciduous sites, 
Fig. 2 Relationship between open-field $T_{\max }$ and belowcanopy/open-field $T_{\max }$ difference at Othmarsingen (beech), Chironico (spruce) and National park (Mountain pine; 1998-2007)

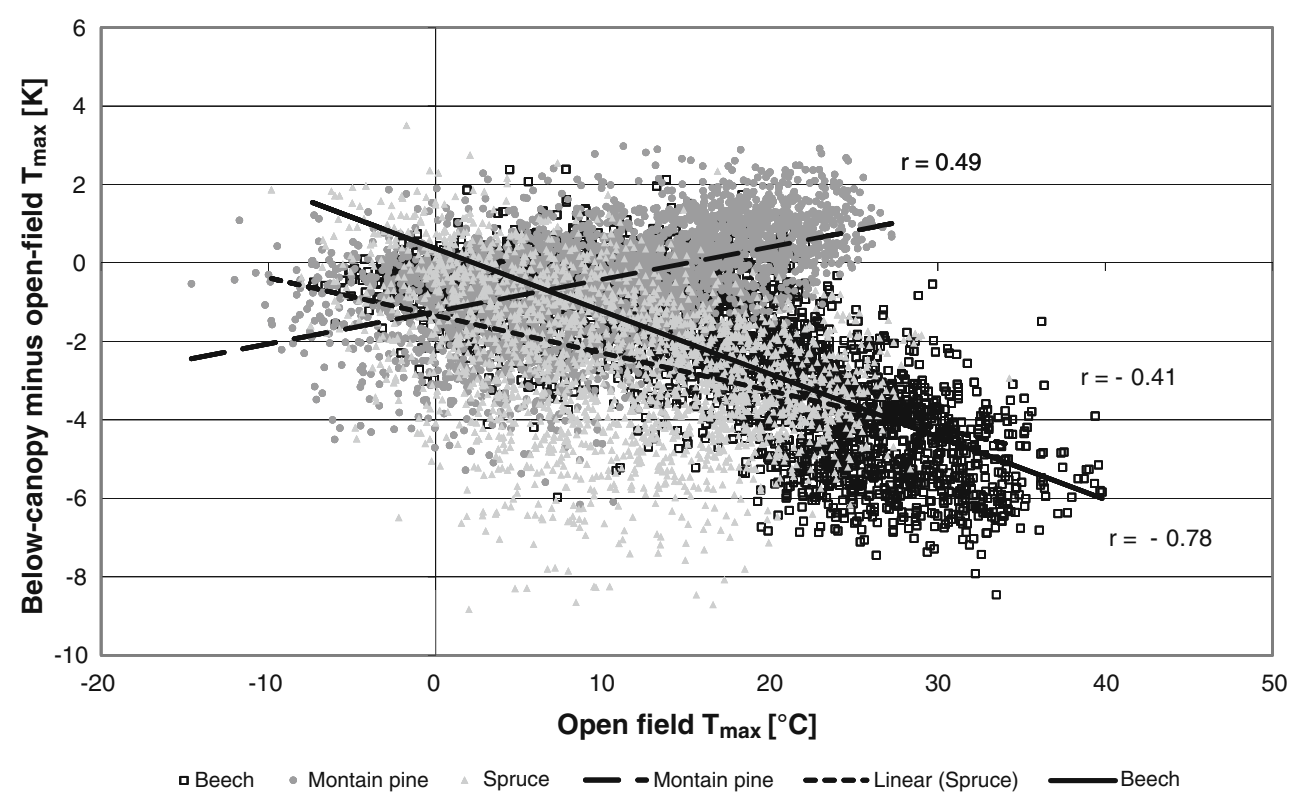

the forest cooling effect was more pronounced in summer 2003 than during the other summers.

An ANOVA test comparing dominant species, slope orientation, basal area and tree height with the discrepancies between below-canopy and open-field confirms $(p<0.0001)$ the influence of these parameters both on $T_{\min }$ and $T_{\max }$.

\subsection{Humidity}

During daytime, relative humidity $\left(\mathrm{RH}_{\min }\right)$ was significantly higher $(p<0.0001)$ below-canopy than in open-field for 13 out of 14 sites (Table 1). The Scots pine site at Visp was an exception with some yearly averages significantly $(p \leq 0.01)$ less humid in the forest than open-field. In the deciduous and mixed forests at medium and high altitudes, $\mathrm{RH}_{\min }$ was most often $10 \%$ to $20 \%$ higher below-canopy than in open-field. Yearly and summer RH averages were almost always significantly higher $(p<0.0001)$ below-canopy than in openfield (up to $17 \%$ ). In winter, at these sites, the $\mathrm{RH}_{\text {min }}$ difference between below-canopy and open-field was not significant every year. When it was, we measured up to $22 \%$ more humidity below-canopy. At the conifer sites and at the two high-altitude deciduous sites (beech, oak), the difference between below-canopy and open-field was not always significant. When it was, $\mathrm{RH}_{\min }$ was from $3 \%$ to $9 \%$ higher in the forest. The $\mathrm{RH}_{\min }$ difference between below-canopy and open-field was less pronounced during the summer of 2003 than during the summers of 1998 to 2007 , especially in the deciduous and mixed stands (Fig. 4).

During the night, $\mathrm{RH}_{\max }$ was significantly $(p<0.001)$ lower below-canopy at the north-oriented conifer sites, from $4 \%$ to $15 \%$ on average in the summer and from $4 \%$ to $22 \%$ on average in winter. At the other sites, the difference between below-canopy and open-field was not always significant
Fig. 3 Difference between open-field and below-canopy $T_{\max }$ and $T_{\min }[\mathrm{K}]$ for the 1998-2007 and 2003 summer average

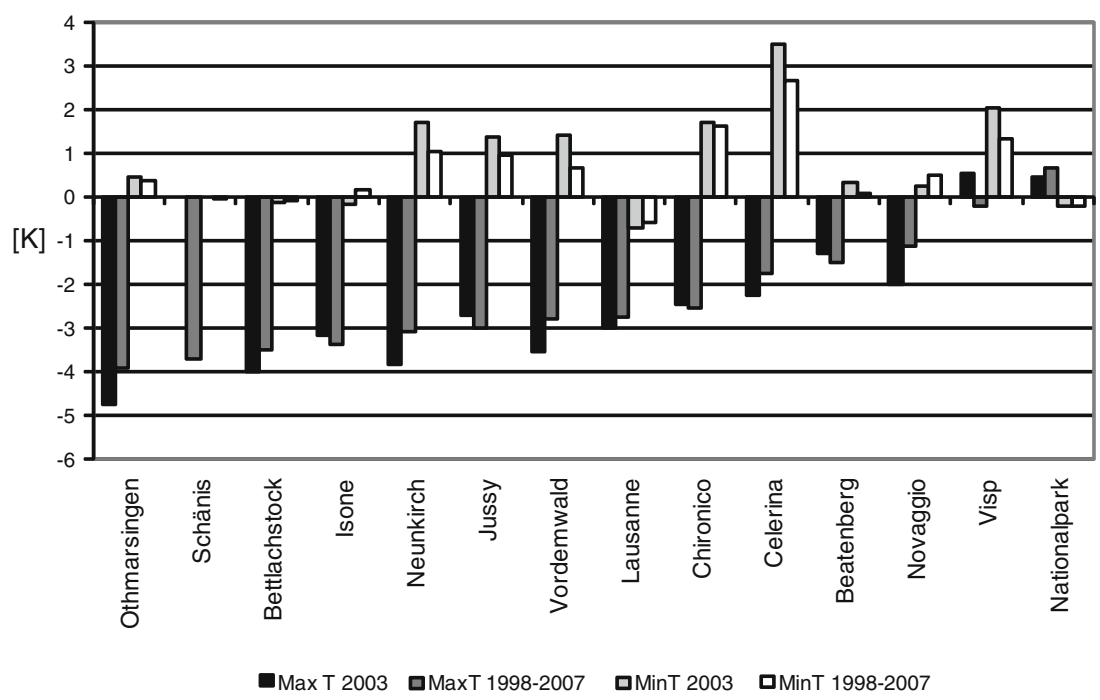


Fig. 4 Difference between open-field and below-canopy $\mathrm{RH}_{\min }$ and $\mathrm{RH}_{\max }[\%]$ for the 1998-2007 and 2003 summer average

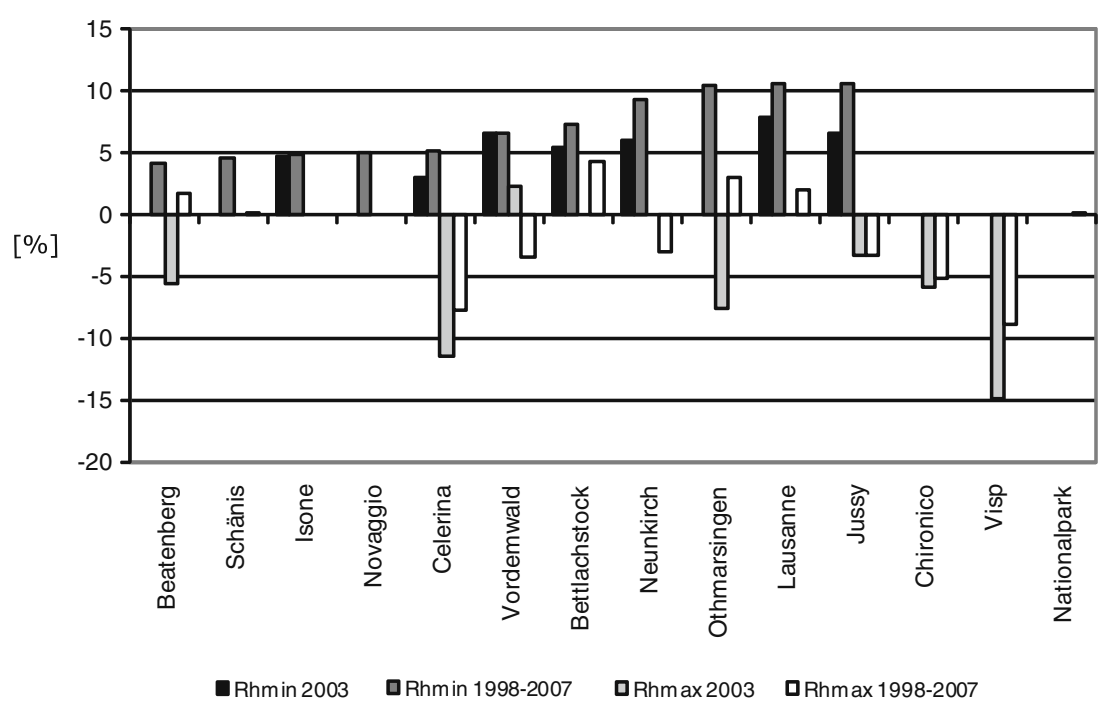

(Table 1). When it was, $\mathrm{RH}_{\text {max }}$ fluctuated from $10 \%$ lower to $13 \%$ higher in the forest. The Pearson correlation coefficient between open-field $\mathrm{RH}_{\max }$ and below-canopy/open-field $\mathrm{RH}_{\text {max }}$ difference could be either positive or negative, depending on slope orientation, as demonstrated in Fig. 5 for south- and north-oriented spruce stands. The $\mathrm{RH}_{\max }$ difference between below-canopy and open-field was generally more pronounced during the summer of 2003 than during the summers of 1998 to 2007, especially in the north-oriented and coniferous stands (Fig. 4).

Daily $\mathrm{RH}_{\text {mean }}$ was generally higher in the forest compared to open-field in summer $(+3 \%$ to $+11 \%)$ but could be either higher or lower in winter $(+12 \%$ to $-7 \%)$, except for the two north-oriented conifer sites where it was clearly lower for the whole period $(-3 \%$ to $-11 \%$ in summer, $-4 \%$ to $-21 \%$ in winter). In the conifer stands, the forest impact was stronger in winter, with the southoriented stands being clearly more humid and the northoriented ones less humid. In deciduous stands, the forest impact was stronger in summer than in winter, with a higher humidity regardless of aspect.
$\mathrm{RH}_{\text {min }}$ and $\mathrm{RH}_{\text {mean }}$ seasonal variability was greater at the Swiss plateau sites, which are characterized by rich clay or silt soils, with high organic activity. Under these specific conditions, $\mathrm{RH}_{\text {min }}$ and $\mathrm{RH}_{\text {mean }}$ were clearly higher belowcanopy than in open-field throughout the observation period, and particularly so in summer, as shown in Fig. 6a for the Neunkirch site. At the plateau sites, $\mathrm{RH}_{\max }$ fluctuated abruptly in the open-field between more and less humid periods, while it was more constant below the canopy, as shown in Fig. 7a for the Vordemwald site. $\mathrm{RH}_{\text {min }}$ and $\mathrm{RH}_{\text {mean }}$ seasonal variability was lower in the highaltitude sites in the Alps, which are characterized by podsolic soils. Generally, these conditions are associated with conifer forests, but the specific climate of Ticino (southern side of the Alps) also allows the development of deciduous forests, such as the Isone beech forest (Fig. 6b). On podsolic soils, the forest effect on $\mathrm{RH}_{\text {min }}$ was less significant, even in deciduous stands, and $\mathrm{RH}_{\max }$ was clearly lower below-canopy than in open-field situations, especially in the north-oriented pine forests such as at Celerina (Fig. 7b).
Fig. 5 Relationship between open-field $\mathrm{RH}_{\max }$ and belowcanopy/open-field $\mathrm{RH}_{\max }$ difference at Chironico (spruce, N) and Beatenberg (Spruce, S) (1998-2007)

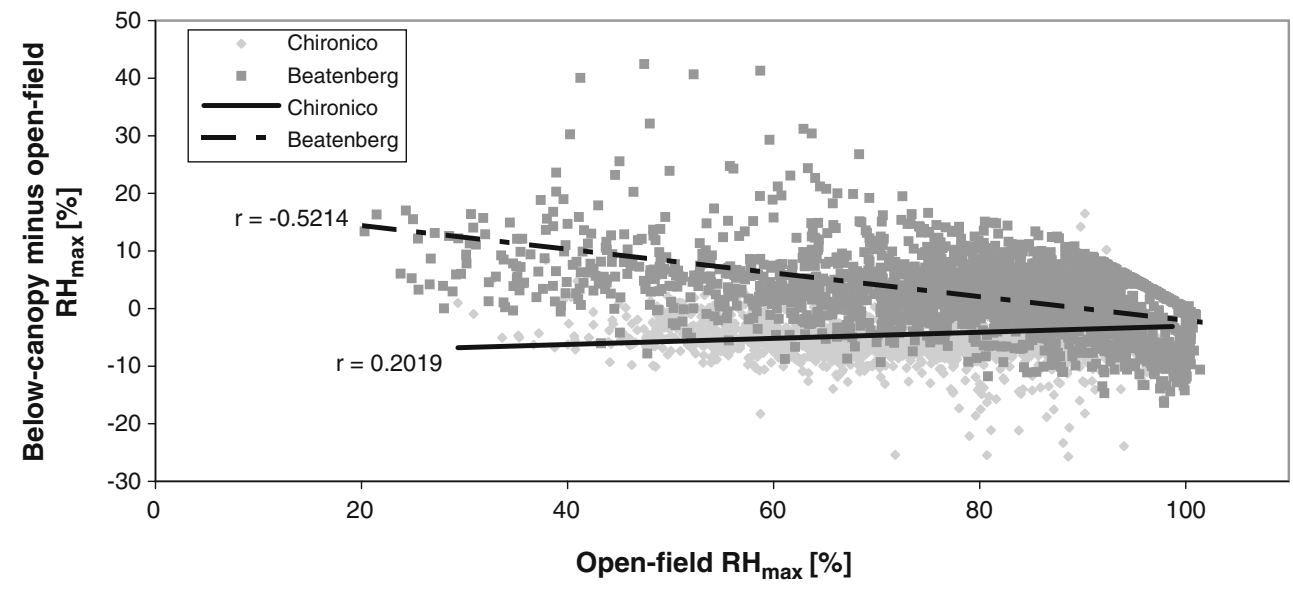



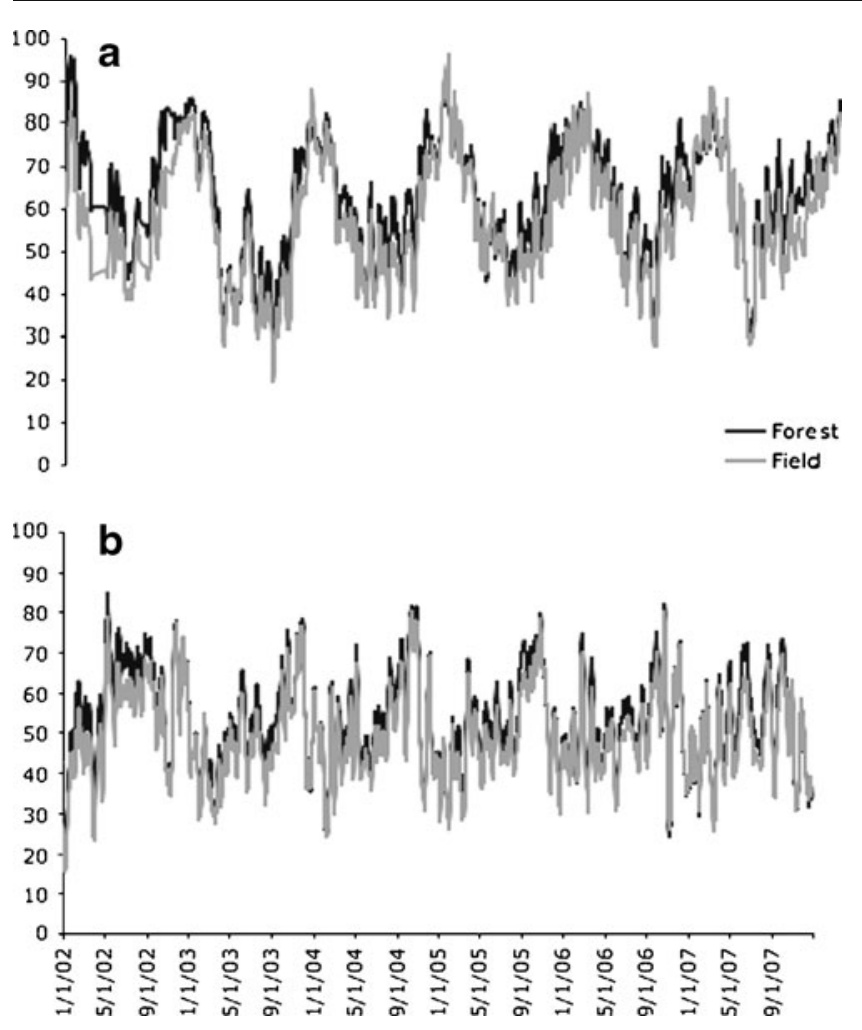

Fig. $6 \mathrm{RH}_{\min }[\%]$ below-canopy and open-field mobile mean (ten periods) at a Neunkirch (mullmoder, beech, N) and b Isone (podsol, beech, N) (2002-2007)

An ANOVA test comparing dominant species, slope orientation and soil type with the differences between below-canopy and open-field confirms $(p<0.0001)$ the influence of these parameters both on $\mathrm{RH}_{\min }$ and $\mathrm{RH}_{\max }$.

\subsection{Wind}

Wind speed was significantly $(p<0.0001)$ lower belowcanopy than in open-field for all sites and throughout the measurement period. It was from 6 to $2.5 \mathrm{~m} / \mathrm{s}$ lower on a seasonal and yearly average at the Swiss plateau and Jura sites, and from 2.4 to $0.1 \mathrm{~m} / \mathrm{s}$ lower at most sites on the southern side of the Alps where wind speeds are usually lower. Deciduous forests had a stronger impact in summer, with the presence of foliage enhancing the difference between forests and open-field by up to $0.6 \mathrm{~m} / \mathrm{s}$. Spruce and beech-silver fir stands had a stronger impact on wind speed in winter. For the whole period, the Pearson correlation between open-field and below-canopy/open-field wind speed difference was highly significant $(r>-0.8)$ for ten out of 14 sites. In others words, the faster the wind, the greater the moderating effect of the forest.

An ANOVA test comparing basal area and tree height with the differences between below-canopy and open-field confirms $(p<0.0001)$ the influence of these parameters on maximum wind velocity.

\section{Discussion}

Our results enable a better understanding of the impact of a forest on local winter and summer climate according to the forest type and the main tree species: in winter, conifers and mixed stands had the strongest cooling effect on daytime temperatures. The forest moderating effect on local temperature was noticeable during the night (warmer in the forest) and for daily mean temperatures for south-oriented conifer sites (Norway spruce, arolla pine/European larch, Scots pine). In the beech stands, in contrast, the canopy acted to regulate temperatures, slightly reducing daytime/ nighttime temperature variation. In summer, the moderating effect on local temperature (cooler in the forest) was striking in beech and beech-silver fir forests during daytime and even nighttime minimum temperatures were slightly lower below-canopy. This cooling effect was more pronounced during hot episodes such as occurred in the summer of 2003. In Mountain and Scots pine stands, both night and day temperatures were clearly higher belowcanopy. In spruce, oak and arolla pine/larch stands, the forest cooling effect during daytime was substantial but, at night, the temperatures were higher below-canopy.
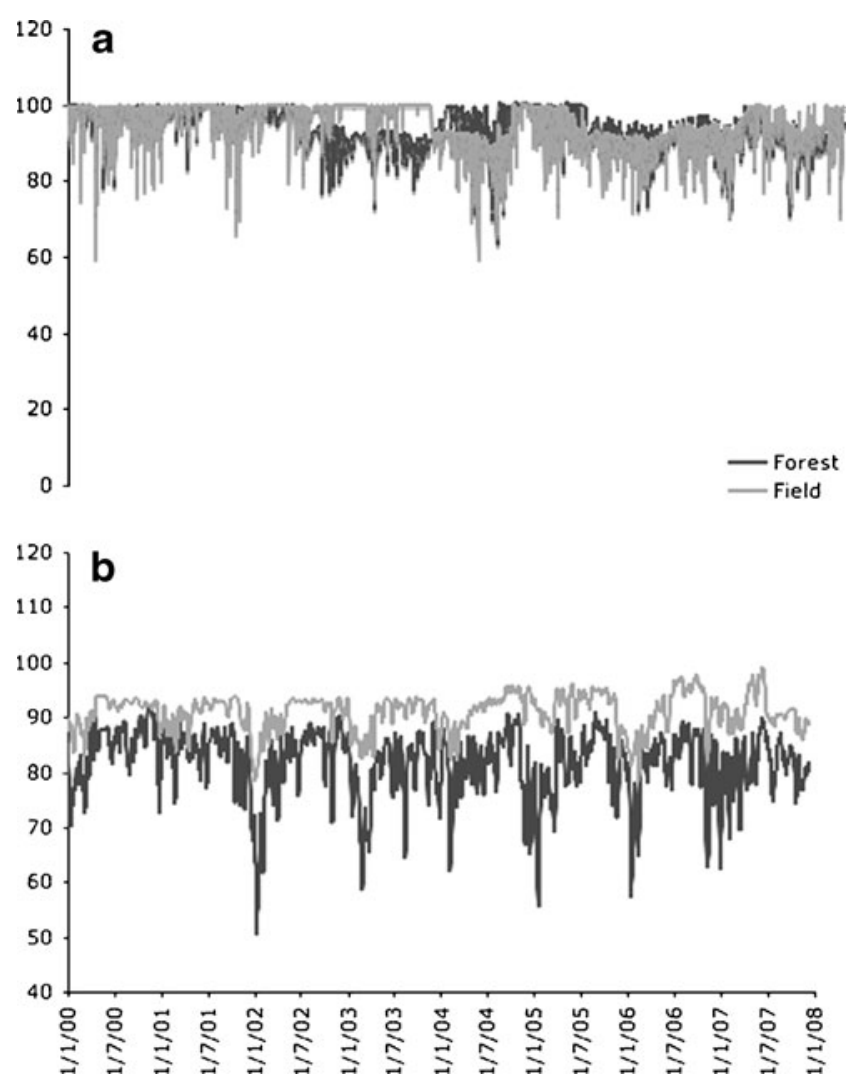

Fig. $7 \mathrm{RH}_{\max }[\%]$ below-canopy and open-field mobile mean (ten periods) at a Vordemwald (mullmoder, silver fir/oak) and b Celerina (podsol, arolla/larch) (2000-2007) 
As previously shown with the comparison of LAI, PAR data and the trees' morphological characteristics (Renaud and Rebetez 2009), the trees' height, mean canopy depth and stand density determine differences in canopy closure. The different structures explain the differences between the effects of beech and pine forests on below-canopy maximum summer temperatures. However, the link between the amount of solar radiation intercepted by the different canopies and the impact on temperatures is not systematic: the arolla pine/larch forest, despite stopping half as much solar radiations as the other pine stands, had a cooling effect on maximum temperatures. This may be explained by the higher stand height of the arolla pines ( $24.4 \mathrm{~m}$ as compared to $14.5 \mathrm{~m}$ for the mountain pines and $8.5 \mathrm{~m}$ for the Scots pine forest). In the same way, the beech and beech-silver fir forests with the more pronounced cooling effect intercepted less solar radiation than other forests with the same composition but with a weaker impact on temperatures.

Basal area and tree height are determinant for the forest impact on maximum temperature for the most extreme cases: the two higher and denser forests indeed have an important smoothing impact on maximum temperature whereas the two lower and less dense forests (the pine forests in Visp and National Park) have a warming effect in summer. But for all the other sites, forest type and dominant species have a stronger impact on maximum temperature. The Spruce forest of Chironico, for instance, although denser and higher than the beech stand of Isone or than the oak stand of Jussy, has a lower cooling effect on maximum temperature. Concerning minimum temperature, dominant factors are aspect and slope.

Forests generally enhanced local humidity, with the effect being particularly marked in deciduous forests during the vegetation period. This is probably due to the more active transpiration in beech stands as compared to conifer stands (Komatsu 2005; Baldocchi and Vogel 1996). The north-oriented conifer sites are an exception with lower humidity in the forest, especially during winter. Our results show that the forest impact on air humidity is related to the water storage capacity of the different soil types: the forest moderating effect on $\mathrm{RH}_{\text {min }}$ (more humid below-canopy than open-field) was lower on podsolic soils. Podsols are characterised by a thick layer of only slightly decomposed organic material. This is important for water storage, which is enhanced by the more frequent precipitation in mountain climates and the snow accumulation during winter. It appears that at the sites used in this study underlain by podsols, the surrounding humidity is regulated more efficiently throughout the year and between dry and humid episodes. Consequently, it seems that the regulating effect of the soil is even stronger than that of the forest type. However, for soils with important seasonal and periodical fluctuations, in terms of either ground-water level or water storage capacity, forest type has a greater impact on $\mathrm{RH}_{\text {min, }}$, and a more local regulating effect, even during summer and during drier periods. In our sample, such soils underlay deciduous and mixed forests.

The Scots pine forest Visp is located in the driest part of Switzerland. Here, evaporation is very high and soil moisture extremely low during summer months (Rebetez and Dobbertin 2004). This was in particularly true in 2003 (Dobbertin and Rigling 2006). Studies at nearby locations have shown that under low soil moisture availability and high vapour pressure deficit Scots pines close their stomata much earlier than deciduous species, such as downy oak (Zweifel et al. 2009). This reduces whole stand transpiration, but also relative air humidity in forests. In July and August 2003, in addition, the leaves of many shrubs, herbs and grasses in Visp had wilted and therefore were also not contributing to transpiration. At the same time, meadows and field next to the open-air climate stations were irrigated. Higher wind velocity in the open as compared to the forest could therefore lead to more humid air being transported to the open station as compared to the belowcanopy station.

The moderating impact on wind speed was significant for all forest types. The difference between the most and least pronounced effects was probably influenced by local plot characteristics. More exposed stands had stronger moderating effects. Indeed, forests height and density do not show any correlation with the discrepancy between open-field and below-canopy wind speed. During summer, the presence of foliage and the higher frequency of convective activity in areas with deciduous and mixed forests brought additional impacts to these sites.

The slope orientation was also a determining factor: in summer, northerly orientations had the greatest impact on minimum temperatures (higher below-canopy), probably due to an inertia effect. This effect was particularly strong at the conifer sites, and was combined with lower nighttime relative humidity throughout the year.

\section{Conclusions}

This analysis of below-canopy climate conditions compared to open-field from 1998 to 2007 at 14 different sites in Switzerland provides information about the impact of forests on local climate. This impact results from a combination of biogeographic stand characteristics, forest type, dominant tree species, topography, slope orientation and soil type. In most situations, the forest has a moderating effect, but under certain conditions, the effect can be intensified.

Deciduous and mixed forests generally had a greater moderating effect during summer and daytime, whereas 
conifer forests had a stronger impact during winter and nighttime. The greatest impacts on summer daytime climate were measured in beech and beech-silver fir stands, provided that the stand structure enabled good wind circulation below-canopy. A southerly aspect increased this moderating influence by maintaining lower night temperatures below-canopy. The strongest moderating impact on winter night climate (warmer temperatures and reduced humidity) was observed in north-facing conifer stands, but conifer forests enhance winter daytime climate (cooler temperatures and higher humidity).

The forest type and dominant tree species primarily determine the forest impact on maximum temperatures, whereas for minimum temperatures, the forest impact results from a combination of dominant tree species and slope orientation. Soil characteristics were the most important parameter determining relative humidity. For wind speed, the forest moderating impact was significant in all cases, but slope orientation, topography and location were the primary variables controlling the strength of the effect. For all meteorological parameters, height and basal area show significant but lower correlations compared to the other factors.

Acknowledgements This work has been supported in part by COST E39 and by the Forest Investigation Program, a joint project of the Swiss Federal Office of the Environment (BAFU) and the Swiss Federal Institute for Forest, Snow and Landscape Research (WSL). We are grateful to Jacques Ferrez, Aurélie Thébault and Yves Trokay for their help with the statistical analyses, to Gustav Schneiter, Peter Jacob and Flurin Sutter for providing data and assistance with the meteorological LWF database and to Brigitte Corboz and Alexandre Buttler for their useful comments and suggestions.

\section{References}

Aussenac G (2000) Interaction between forests stands and microclimate: ecophysiological aspects and consequences for silviculture. Ann For Sci 57:287-301

Baldocchi DD, Vogel CA (1996) Energy and CO2 flux densities above and below a temperate broad-leaved forest and a boreal pine forest. Tree Physiol 16(1-2):5-16

Bastable HG, Shuttleworth WJ, Dallarosa RLG, Fisch G, Nobre CA (1993) Observations of climate, albedo, and surface radiation over cleared and undisturbed amazonian forest. Int J Climatol 13 (7):783-796

Bauer DF (1972) Constructing confidence sets using rank statistics. J Am Stat Assoc 67:687-690

Chen JQ, Franklin JF (1997) Growing season microclimate variability within an old-growth Douglas-fir forest. Clim Res 8(1):21-34

Chen JQ et al (1999) Microclimate in forest ecosystem and landscape ecology - variations in local climate can be used to monitor and compare the effects of different management regimes. Bioscience 49(4):288-297
Dobbertin M, Rigling A (2006) Pine mistletoe (Viscum album ssp austriacum) contributes to Scots pine (Pinus sylvestris) mortality in the Rhone valley of Switzerland. For Pathol 36(5):309-322

Friedland AJ, Boyce RL, Vostral CB, Herrick GT (2003) Winter and early spring microclimate within a mid-elevation conifer forest canopy. Agric For Meteorol 115(3-4):197-202

Geiger R, Aron RH, Todhnter P (2003) The climate near the ground. Rowman \& Littlefield, Lanham, 584pp

Grimmond CSB, Robeson SM, Schoof JT (2000) Spatial variability of micro-climatic conditions within a mid-latitude deciduous forest. Clim Res 15(2):137-149

Holst T, Mayer H, Schindler D (2004) Mircoclimate within beech stands - part II: thermal conditions. Eur J Forest Res 123:1328

Holst T, Rost J, Mayer H (2005) Net radiation balance for two forested slopes on opposite sides of a valley. Int J Biometeorol 49(5):275284

Innes JL (1995) Theoretical and practical criteria for the selection of ecosystem monitoring plots in Swiss forests. Environ Monit Assess 36(3):271-294

Komatsu H (2005) Forest categorization according to dry-canopy evaporation rates in the growing season: comparison of the Priestley-Taylor coefficient values from various observation sites. Hydrol Process 19(19):3873-3896

Lee R (1978) Forest microclimatology. Columbia University Press, New York

Logeay G, Rebetez M (1999) Etude comparative de données enregistrées par les stations météo LWF et SMA de Reckenholz et Visp-Rapport interne, WSL-Switzerland

Matsumoto K et al (2008) Energy consumption and evapotranspiration at several boreal and temperate forests in the Far East. Agric For Meteorol 148(12):1978-1989

Merklova L, Bednarova E (2007) Microclimate in a spruce and beech stand, bioclimatology and natural hazards. Polana nad Detvou, Slovakia

Morecroft MD, Taylor ME, Oliver HR (1998) Air and soil microclimates of deciduous woodland compared to an open site. Agric For Meteorol 90(1-2):141-156

Pavari A (1959) Les influences de la forêt. Unasylva 13(1)

Porte A, Huard F, Dreyfus P (2004) Microclimate beneath pine plantation, semi-mature pine plantation and mixed broadleaved-pine forest. Agric For Meteorol 126(1-2):175-182

Rebetez M, Dobbertin M (2004) Climate change may already threaten Scots pine stands in the Swiss Alps. Theor Appl Climatol 79:1-9

Rebetez M, Reinhard M, Büttler A (2004) Forests, tree physiology and climate. Encyclopedia of Forest Sciences, London, pp 1644 1655

Renaud V, Rebetez M (2009) Comparison between open-site and below-canopy climatic conditions in Switzerland during the exceptionally hot summer of 2003. Agric For Meteorol 149 (5): $873-880$

Schleppi P, Conedera M, Sedivy I, Thimonier A (2007) Correcting non-linearity and slope effects in the estimation of the leaf area index of forests from hemispherical photographs. Agric For Meteorol 144:236-242

Xia YL, Fabian P, Stohl A, Winterhalter M (1999) Forest climatology: reconstruction of mean climatological data for Bavaria, Germany. Agric For Meteorol 96(1-3):117-129

Zweifel R, Rigling A, Dobbertin M (2009) Species-specific stomatal response of trees to drought - a link to vegetation dynamics? J Veg Sci 20(3):442-454 